\title{
Students' Reading Comprehension Performance with Emotional Literacy-Based Strategy Intervention
}

\author{
Yusfarina Mohd Yussof (corresponding author) \\ Faculty of Educational Studies, Putra University of Malaysia, \\ 43300 UPM Serdang, Selangor, Malaysia. \\ E-mail: yusfarina@yahoo.com \\ Abdul Rasid Jamian \\ Faculty of Educational Studies, Putra University of Malaysia, \\ 43300 UPM Serdang, Selangor, Malaysia. \\ E-mail: arasid@putra.upm.edu.my \\ Zaitul Azma Zainon Hamzah \\ Faculty of Modern Languages and Communication, Putra University of Malaysia, \\ 43300 UPM Serdang, Selangor, Malaysia. \\ E-mail: zaitul@fbmk.upm.edu.my \\ Samsilah Roslan \\ Faculty of Educational Studies, Putra University of Malaysia, \\ 43300 UPM Serdang, Selangor, Malaysia. \\ E-mail: samsilah@educ.upm.edu.my
}

Received: 17-05- 2013

doi:10.7575/aiac.ijels.v.1n.1p.82
Accepted: 27-06- 2013

Published: 01-07- 2013

URL: http://dx.doi.org/10.7575/aiac.ijels.v.1n.1p.82

\begin{abstract}
An effective reading comprehension process demands a strategy to enhance the cognitive ability to digest text information in the effort to elicit meaning contextually. In addition, the role of emotions also influences the efficacy of this process, especially in narrative text comprehension. This quasi-experimental study aims to observe students' performance in the Reading Comprehension Test resulting from Emotional Literacy-Based Reading Comprehension Strategy (ELBRCS), which is a combination of cognitive and affective strategies. This study involved 90 students, whereby 45 students were clustered in the Experimental Group and received the ELBRCS intervension. The remaining 45 students were placed in the Control Group and underwent the conventional strategy (prevalent classroom method).The students' reading comprehension performance was measured using the Reading Comprehension Test (RCT). The findings show that the experimental group received a higher score than the control group for RCT. The intervention has successfully increased student's Reading Comprehension from literal comprehension to higher levels of comprehension i.e. inferential, evaluative and appreciative levels, as indicated by Barret's Taxonomy.
\end{abstract}

Keywords: Strategy; Reading Comprehension; Emotional Literacy; Barret's Taxonomy

\section{Introduction}

Reading comprehension is a meaning making process that demands readers' active role in integrating their schemata with the writers' linguistic background with the help of repertoire strategies (Barr, Blachowicz, Katz \& Kaufman, 2002; Harp, 2004). Its efficacy depends on the use of strategy that enhances the meaning construction process. According to Mahzan (2008), a strategy will facilitate and help reader achieve the reading goal much faster. In this context, an effective strategy, according to Spiro (1984) and Tang and Moore (1992), is a strategy that gives equal focus on cognitive, metacognitive and affective aspects. This is to ensure that the reading comprehension process is thinkingoriented and will lead to a high level of comprehension and optimal output-cognitively and affectively-especially in a narrative text comprehension. The ultimate goal of narrative text comprehension is to reach the affective level. In narrative text comprehension the students have to show their appreciation towards the plot and character until their emotions are released as an affective response towards narrative text reading. According to Barrett's Taxonomy (Figure 1), 'Appreciation' is the highest level in the cognitive thinking hierachy. 


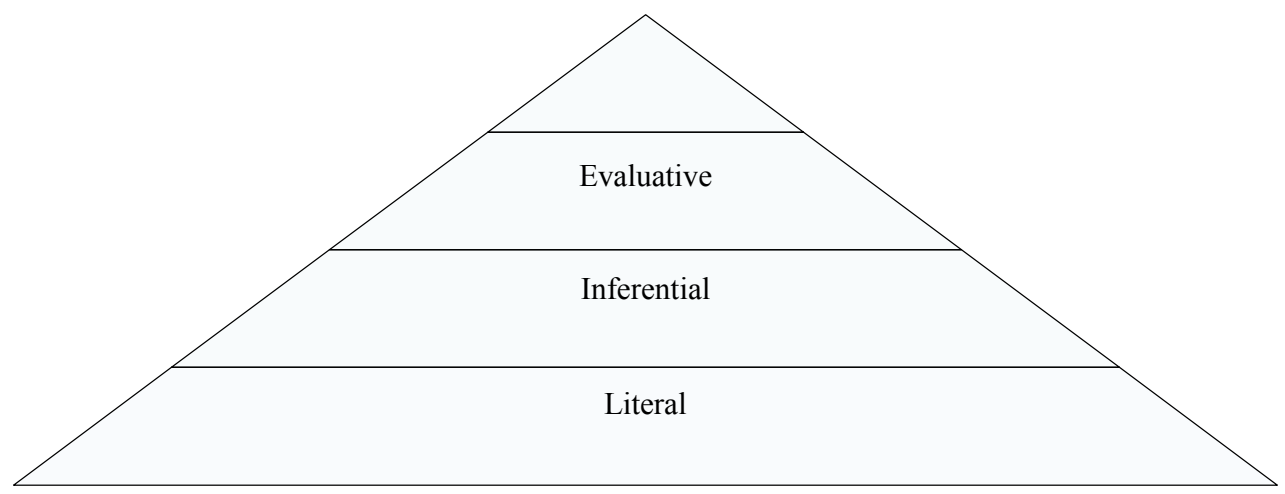

Figure 1. Barret Taxonomy

Source : Barret and Smith (1974).

Equal focus on both cognitive and affective aspects in learning is also parallel to Malaysian National Education aspiration that aims to generate human capital within the international educational environment through mastering of high level knowledge and bilingual proficiency, while strongly upholding the value and spiritual aspects (Malaysian Education Blueprint, 2013-2025). Apart from cognitive constructs, affective constructs such as value, spiritual, motivation and emotion also influence an individual's skills and success. Moreover, individual's achievement today is measured not only via Cognitive Quotient (IQ), but also through Emotional Quotient (EQ) that has been recognized as equally important to EQ in determining individual success (Daus \& Ashkanasy, 2005; Mohd Azhar, 2006). EQ psychometrically is a type of intelligence (Daus \& Ashkanay, 2005) and is also perceived as a value-based concept (Roffey, 2009). This concept is defined by Salovey, Mayer and Caruso (2004), as a skill that enables individual to evaluate self-emotion and emotion of others accurately, to expresses self-emotion and to be able to control emotion, thought and action. The term Emotional Quotient was coined by an Isreali psychologist, Reuven Bar-On (1997) in the effort to place Emotional Intelligence at par with Intelligence Quotient (IQ). The Emotional Intelligence is used in the United States to explain a similar concept with Emotional Quotient, and Emotional Literacy is a term used in the United Kingdom. For the context of this research, the term Emotional Literacy (EL) will be used. Nevertheless, the term EQ will still be used in this article for related discussion. In this research, an EL-based reading comprehension strategy is used on narrative texts to help improve students' reading comprehension i.e. from a literal comprehension level to a higher cognitive level and eventually, to the affective level. At the affective level, students would be able to appreciate the narrative texts and express their emotional responses.

The correlation between EQ and language is evident from the studies carried out by Rahimi, Sadighi and Fard (2011), Zarafhan and Ardeshiri (2013) and, Talebinejad and Fard (2012). In the reading comprehension context, studies have found positive correlation and significant relationship between reading comprehension and EQ (Agandi, 2009). Similar findings are also identified in studies that applied cognitive and affective based reading interventions, in which increases in EQ are reported as a result of implementing such strategy (Rouhani, 2008; Khazaeenezhed \& Talebinezhad (2011).

\section{Research Significance}

The study on the strategy is significant because one of the factors that contribute to the weakness in reading comprehension has been identified as a result from the failure to practice an effective strategy (Dymock, 1993). An effective strategy refers to a strategy with balanced emphasis on cognitive, metacognitive and affective domains (Spiro, 1984; Tang \& Moore, 1992). The use of a balanced and suitable strategy is expected to contribute to proficient reading skills and far better reading comprehension skills, as well as high cognitive and affective levels of reading comprehension mastery within one simultaneous learning session.

\section{Research Objective}

The objective of this research is to study the effectiveness of ELBRCS in enhancing students' reading comprehension mastery. Specifically, it is to determine the ELBRCS intervention effect in contrast to the conventional strategy in increasing RCT scores among the students studied.

\section{Research Scope}

In this study, the researcher views affective construct (emotion and Emotional Literacy) as a factor that influences reading and also as an output of the reading comprehension process towards narrative text. However, only the reading comprehension output will be measured using Reading Comprehension Test (RCT) score. RCT comprises items from literal, inferential, evaluative and appreciation (affective) levels. Students can attain the affective level when they are able to appreciate and give responses to author's hidden messages. When students focus on emotion (as an affective construct), they would be able to emulate the characters and plots in the narrative text, and thus arrive at the desired output i.e. total comprehension of the text. 


\section{Problem Statement}

EQ is beneficial to individuals and should be instilled from the preliminary stage. This process is identified through this trifecta: family, environment and education (Shahabudin, Mahani \& Ramlah, 2007). As educators are seen as significant individuals in channelling experiences and teaching in inculcating EQ (Bundy \& Cornwell, 2009), EQ ought to be integrated in the existing curriculum (Weare, 2004).

To date, studies have proven the importance and influence of EQ in enhancing academic achievement (Ogundokun \& Adeyomo, 2010; Azizi, Ng, Juriah, Noordin, Yusof, Shahrin \& Goh, 2012). In addition, EQ is also associated to effective language learning (Rahimi, Sadighi \& Fard, 2011; Zarafhan \& Ardeshiri, 2013; Talebinejad \& Fard, 2012). As for reading comprehension, Agandi (2009) reported positive correlation and significant relationship between reading comprehension and EQ. Similarly, research related to cognitive-and-affective-based reading interventions show an increase in EQ scores (Rouhani, 2008; Khazaeenezhed \& Talebinezhad (2011)

Based on studies above, the relationship between language and EQ is clear, especially through the language learning session that combines both cognitive and affective aspects. Nonetheless, Brackett and Katulak in Bahareh and Reza (2011) commented that the studies that relate EQ with language are mostly in English Language. Thus, to fill up the research gap, this research integrates EQ in the aspect of learning Malay Language as the first language in Malaysia. Weare's (2004) perspective on integration of EQ in curriculum has been made a basis framework of the research. In this research the EQ integration is channelled through a reading comprehension strategy combining both cognitive and affective startegies.

\subsection{Study hypothesis}

The null hypotheses to be tested are as follows:

$H_{01}$ :

No significant difference between the RCT mean scores of both tests (Pre and Post) for the Experimental Group and the Control Group.

\subsection{Literature Review}

In linguistic context, the effect of implementing reading strategies based on cognitive and affective aspects in improving EQ has been proven. For instance, Khazaeenezhed \& Talebinezhad (2011) have conducted an experimental study upon 80 students in Linguistic Institute, Iran. The study, which utilized an open-ended narrative text in cognitive-affective reading course for English language learning session, has shown EQ improvement as a result of the intervention. Research by Rouhani (2008) investigate the effectiveness of the cognitive-affective reading course intervention towards four constructs (Emotional Intelligence, Emotional Quotient, Anxiety and Empathy) for the first and second year students of Shahrekord University, Iran. This result shows the mean increase for all constructs, except for anxiety.

However, there are also studies examining the effect of EQ as an independent variable in influencing linguistic proficiency. For example, the study by Rahimi et. al. (2011), who observed EQ and Linguistic Intelligence in affecting the Iranian students' ability to learn English as a second language, found a negative correlation between EQ and reading ability but it was otherwise for the Linguistic Intelligence. Zarafshan and Ardeshiri's (2012) study of 135 Iranian undergraduates (specializing in English Language Teaching and Translation), finds negative correlation between EQ and English language learning strategy. As far as the effects of EQ are concerned, these two studies show contradicting results in terms of reading comprehension mastery.

Studies related to EQ and reading comprehension show positive association (Agandi, 2009). For instance, Talebinejad and Fard (2012) investigated the relationship between EQ and socio-economic status (SES) with reading comprehension, for 80 female students (aged 14-17) in Eghlid, Iran. The results revealed significant relationships. Motallebzadeh (2009) who conducted a study on 250 English language students in Azad Islamic University, Iran found a strong correlation between all domains (except empathy and social responsibility domains) and individual structural ability with reading comprehension.

Literature in this context also clarifies the importance of reading comprehension learning based on EQ. Among them is the perspective of EQ implementation proposed by Iquinta and Hipsky (2009) that outlined four stages of selfexploration by the students in a reading comprehension process. In the same context, Shaw and Aslanian (2010) proposed 4 different steps in implementing EQ in reading class. They suggested deep comprehension process and connection with self and environment. Even though the methods suggested by both scholars are clearly different, fundamentally the methods are to create solid comprehension and to incite students' self-exploration as the basis in text interpretation, particularly in narrative texts.

In general, the literature review indicates that studies relating EQ to language learning are generally divided into two: some observe EQ as an independent variable and its effect towards language mastery, while others observe EQ as a dependent variable, as the output to the given intervention. This research falls under the second category. In this research, the reading comprehension mastery is the output to the reading comprehension process resulting from the given Emotional Literacy Based Reading Comprehension Strategy.

\subsection{Related Theory}

Since this study focuses on cognitive and affective strategy in aiding the reading comprehension mastery, the theories used are cognitive theory (Constructivism) and affective theory (EQ Theory). 
Based on Constructivism Theory, students will be exposed to the:

- Critical ideas in the text,

- Conflicts of the characters in the narrative text,

- Themes and questions that are established through this EL-based strategy.

The students' role as meaning builder is stressed, inline with the basic assumptions of constructivism. Through this strategy, students will be able to (1) express their interpretation in words; (2) self-relate themselves with the text; (3) identify the similarities or differences, and (4) make self-reflections in the presence of teachers' guidance. These are conducted in a safe discussion environment until the students are ready to acquire the learning process as autonomous learners (Macahado, 2010). The autonomous learning can be achieved through students' self-exploration process and meaning construction. This concurs with the basic assumption in constructivism that stresses on the students' role as a constructive meaning builder. New knowledge constructed and new understandings developed are resulted from students' self-exploration. Teachers only play a minimal role as a facilitator who gives out instructions.

The supporting theory for this study is the Emotional Quotient (EQ) Theory. EQ is one of the contructs in the affective domain that can be related to the reading process. The emotional construct can be an influence in the cognitive-based meaning making process. The relationships and influence of emotions in cognitive process have been explained by Salovey and Mayer (1990), who define EQ as one's ability to control self-emotions and the emotions of others, can differentiate emotions, and use this information in controlling their thoughts and actions. In a reading process, readers can create text meaning through the interaction of idea and text, and the interaction of text with the readers' minds. The interaction of text with the readers' minds, apart from increasing the readers' cognitive level, can stimulate the affective domain by reflecting the readers' emotions. This situation conforms to the assumption in the EQ Theory that supports the relation between cognitive and affective (emotions). When readers read, they will try to elicit their suppressed feelings and emotions (Barr, 2002). The emotions expressed through this reading process help individuals to be aware of their emotions. Thus, learning strategy that emphasises affective aspect is expected to bring an increase in EQ because it gives opportunity for the students to express and understand their emotions better. This will lead to a far more effective self-regulation of their emotions. In addition, the students would be more sensitive in understanding the emotions of others. Through the understandings of own and others' emotions and, good control and management of emotions, Emotional Literacy can be attained.

\section{Research Methodology}

\subsection{Sampling}

The population of this study was Form Two secondary school students (with an average age of 14) in Selangor, a state in Malaysia. The accessible population, which was the subset of the target population, was Form Two students in Hulu Langat, a district of Selangor. The Sampling Frame represented the total of Form 2 students from 39 secondary schools in Hulu Langat district. The number of schools and their names were provided by the District Education Office officer. From this sampling frame, a school was selected based on Clustered Random Sampling category and 90 Form 2 students were chosen from the school.

\subsection{Research Procedure}

This study adapted a quasi-experimental with a non-equivalent group pre-post test design and was conducted for a duration of 8 weeks. The researcher used two intact classes, as the school management did not allow random distribution and selection of samples. The dependent variable (DV) was measured using the scores obtained from the Reading Comprehension Test (RCT) that measured students' reading comprehension. RCT was administered upon the completion of ELBRCS intervention (for the Experimental Group). Simultaneously, the Control Group received a conventional strategy (the prevalent classroom method). ELBRCS intervention combined several reading comprehension strategies (cognitive and affective) that were conducted orally and in written form.

In practice, students' cognitive level was stimulated by guided questions that were asked by fasilitator [Examples of guided questions are included in Appendix 1]. The guided questions focused on deep comprehension with the purpose of achieving higher levels of literal comprehension (Yusfarina, Abdul Rasid, Zaitul Azma, Samsilah \& Maslawati, 2012). Through this strategy, the students' cognitive and affective aspects were disclosed and the increase in cognitive and affective levels contributed to their reading comprehension mastery. Students' affective aspects were generated by encouraging students to focus on the beauty of the plots or storylines and to share the feelings triggered upon reading the text. Furthermore, this affective level was achieved through appreciation towards emotions that were experienced by the characters in the narrative text. Students were also encouraged to self-reflect by giving evaluation on the characters' emotions and their own emotions that developed through reading the text. Students were guided to use this strategy until they become adept and used it on their own in other learning activities. This strategy was aligned with Gunning's (2008) six steps implementation of reading comprehension strategy, kickstarting with simple reading activity and ending with a more complex activity.

\subsection{Instrument}

Students' Reading Comprehension performance level was measured by Reading Comprehension Test (RCT), which was constructed by the researchers based on the Barret's Taxonomy, a hierarchy of thinking levels for reading comprehension process. The Barret's Taxonomy was represented by literal and inferential levels (cognitive), evaluative level (a superposition of cognitive and affective), and finally appreciation level (affective) that referred to text appreciation and elicited emotional responses (Barret, 1974). The RCT contained 30 items in total, consisted of 16 
literal level questions, 6 inferential level questions, 3 evaluative questions and 4 affective level questions. This instrument had undergone the validity process, and its reliability was tested using the KR20 Method - a value of 0.65 , deemed as suitable and acceptable (Majid, 2005).

\section{Findings}

\subsection{Statistical Analysis}

The obtained data were analysed using "Statistical Package for the Social Science" software (SPSS) version 19. The result is reported in the form of inferential statistics for the purpose of testing the research hypothesis and descriptive statistics.

\subsection{Hypothesis Testing for the Experimental Group Reading Comprehension Test (RCT) score}

The Anova (Mixed Design) analysis administered with the two groups (control and experimental) shows a significant interaction. The obtained Wilk's Lambda value is 0.525 with the significant value $(\mathrm{p})=0.000$ (lesser than $\alpha$ value), $\mathrm{F}=(1,88)=79.7$ and partial eta value $=0.475$. Please refer to Table 1 :

Table 1: ANOVA Mixed Design Test for Control and Experimental Groups RCT score

\begin{tabular}{lllll}
\hline Interaction/Effect & Wilk's Lambda & F & Sig. P & Partial eta $^{2}$ \\
\hline Interval*Group & 0.525 & 79.677 & 0.000 & 0.659 \\
\hline Interval/Test & 0.341 & 170.305 & 0.000 & 0.475 \\
\hline $\mathrm{p} \leq 0.05$ & & & &
\end{tabular}

The null hypothesis is rejected because the significant value(p) is less than $\alpha$ value, 0.05 . This shows that the test/interval interaction with the groups affects the score difference between groups. This combination/interaction affects or brings different change rate towards both groups.

Table 2: Descriptive Data in RCT Mean Score Comparison for Control and Experimental Groups

\begin{tabular}{|c|c|c|c|c|c|}
\hline \multicolumn{2}{|c|}{ Group } & \multicolumn{2}{|c|}{ Control } & \multicolumn{2}{|c|}{ Experimental } \\
\hline Test & $\mathrm{N}$ & Mean & $\begin{array}{l}\text { Standard } \\
\text { Deviation }\end{array}$ & Mean & $\begin{array}{l}\text { Standard } \\
\text { Deviation }\end{array}$ \\
\hline Pre & 45 & 53.26 & 6.4201 & 54.14 & 8.5025 \\
\hline Post & 45 & 59.63 & 9.1305 & 55.34 & 8.9470 \\
\hline
\end{tabular}

From the mean score table (Table 2), it is found that the experimental group show cases more increment than that of the control group. The increment can be associated to the affects of the different interventions received by both groups. Hence, it canbe concluded that the ELBRCS intervention received by the experimental group is more effective than the conventional intervention in increasing the responding variable, RCT. Based on the obtained eta effect value $=0.659$, the effect that is demonstrated by this eta value is medium rate effect (Cohen, 1988). This explains that the effect of the test/interval interaction with the groups affects the increase in the RCT score at medium level.

\section{Discussion}

The increment in the RCT mean scores (data for the experimental group) can be associated with the different interventions received by both groups. Hence, it can be concluded that the ELBRCS was more effective than the conventional intervention in increasing RCT. This gives an implication that ELBRCS is more effective in improving the students' reading comprehension mastery from the aspects of cognitive and affective (emotion and EL) when compared to the conventional method.

The positive effects of implementing this cognitive-affective strategy support the studies done by Khazaeenezhed and Talebinezhad (2011) and Rouhani (2008) that show EQ improvement (affective) via cognitive-affective intervention. The results of these studies are also in tandem with the study by Talebinejad \& Fard (2012) that unearths the significant relation between EQ and SES with reading comprehension, and also parallels with the study by Motallebzadeh (2009) that finds a strong correlation between reading comprehension and all of the EQ domains (excluding empathy and social responsibility domains). Nevertheless, the result of this study clashes with the study by Rahimi et. al. (2011) that shows a negative result between EQ and reading capability, and the study by Zarafhan and Ardeshiri (2012) that observes the negative relationship between EQ with English language proficiency strategy.

Collectively, the usage of the intervention of cognitive-affetive strategy is able to increase the cognitive (from literal to higher level) and affective domain (EQ) in reading comprehension. Moreover, EQ also shows a strong correlation as a variable that can improve reading comprehension mastery. 


\section{Conclusion}

In conclusion, this research provides a meaningful contribution in proving that the implemented ELBRCS strategy does not only increase the cognitive domain in reading comprehension, but is also effective in increasing the affective domain, which comprises of emotion and EQ. The implication towards research findings is that the Emotional LiteracyBased Reading Comprehension Strategy can be used for increasing the mastery on reading comprehension. While helping to upgrade the thinking level from low cognitive level to high cognitive level, this strategy also helps to achieve the affective level amongst secondary school students studied.

\section{References}

Agandi, S. (2011). A Study of Emotional Intelligence in Relation To Reading Comprehension of Secondary School Student, International Refereed Research Journal, May, 2011.vol.iii(28A), 19-21.

Azizi, Y., Ng, S.,Juriah, B., Noordin, Y.,Yusof, B., Shahrin, H. \& Goh, M., (2012) . The Impact of Emotional Intelligence Element on Academic Achievement, Archives Des Sciences, April 2012, Vol. 65, No. 4, 2-17.

Bar-On, R. (1997). The Emotional Quotient Inventory (EQ-i): a test of Emotional Intelligence. Toronto Canada: Multi Health System, Inc.

Barr, R. (2002). Reading Diagnosis For Teachers-An Instructional Approach, 4th Edition. Boston, U.S.A.: Allyn and Bacon

Barr, R., Blachowicz, C. L., Katz, C., \& Kaufman, B. (2002). Reading Diagnosis for Teachers: An Instructional Approach. Boston: Allyn and Bacon.

Barret, T. \& Smith, R. (1974). Teaching Reading in The Middle Grades, Reading. Wisconsin. U.S.A.: Addison Wesley Publishing Company.

Bundy, J \& Cornwell, S. (2009). The Emotional Curriculum: A Journey Towards Emotional Literacy. United Kingdom: Publisher: Sage Publications Ltd.

Cooper, R. (1997). Executive EQ: Emotional Intelligence in Leadership and Organization. New York, U.S.A.: A Perigee Book.

Cohen, J. (1988). Statistical Power Analysis for the Behavioural Sciences (2 ${ }^{\text {nd }}$ Ed.). U.S.A: Lawrence Erbaum Associates, Inc.Publishers.

Daus, Catherine S. \& Ashkanasy, Neal M. (2005). The Case for the Ability Based Model of Emotional Intelligence In Organizational Behaviour. Journal of Organizational Behaviour (2005), 26(4); 453-466.

Gunning, T. (2008). Creating Literacy Instruction For All Students in Grades 4-8, 2nd Edition. U.S.A.: Pearson Education, Inc.

Harp, B., (2004). The Informed Reading Teacher: Research-Based Practice. New Jersey, U.S.A.: Prentice Hall.

Idol, L (1987). "Group Story Mapping: A Comprehension Strategy For Both Skilled and Unskilled Readers", Journal of Learning Disabilities, 20 (1987):199.

Iquinta, S. (2006). Bibliotheraphy for Inclusive Classroom. Retrieved August 9, 2009, from http://www.newhorizons.org/speeds/inclusin/teaching/hipsky_iaquinta

Khazaeenezhed, B. \& Talebinezhad, M. (2011). Emotional Intelligence and Cognitive-Affective Reading-Based Courses: The Case of Reading Open-Ended Stories. The Iranian EFL Journal www.iranian-efl-journal.com/February2011-Vol 7-1.pdf

Malaysian Education Blueprint(2013-2025), September 2012 access on 13 Sepetember from http://www.moe.edu.my/btp/wp-content/uploads/2012/Blueprint/Preliminary-Blueprint-BM.pdf.

Majid Konting (2005). Kaedah Penyelidikan Pendidikan. Kuala Lumpur: Dewan Bahasa dan Pustaka.

Mayer, J., Salovey, P., \& Caruso, D. (2004). Emotional Intelligence: Theory, Findings and Implications: Psychological Inquiry, 2004, Vol 15, No.3, 197-215

Mohd Azhar Hamid. (2006). Panduan Meningkatkan Kecerdasan Emosi. Skudai, Johor Bahru: Penerbit Universiti Teknologi Malaysia (UTM)

Motallebzadeh, K (2009), The Relationship Between Emotional Intelligence of Iranian EFL Learners and Their Reading Comprehension and Structural Ability, Journal Of Teaching English as a Foreign Language and Literature, Islamic Azad University, North Tehran Branch, 1(14), Fall, 2009, 39-55.

Ogundokun, M. \& Adeyemo, D. (2010), Emotional Intelligence and Academic Achievement: The Moderating Influence of Age, Intrinsic and Extrinsic Motivation, The African Symposium: An Online Journal of the African Educational Research Network, Vol.10, No.2, December 2010, 127-141.

Oxford, R. (1994), Language Learning Strategies: An Update, Online Resources Digest, http://www.cal.org/resources/digest/oxford0.1html 
Rahimi, M., Sadighi, F., \& Fard, Z. (2011). The Impact of Linguistic and Emotional Intelligence on The Reading Perfomance of Iranian EFL Learners, The Journal of Teaching Language Skills (JTLS), (Previously Journal of Social Sciences and Humanities), 3(1), Spring, 2011, 150-171

Roffey, S. (2009). Circle Time for Emotional Literacy. Singapore: Sage Publication Asia Pacific Sdn.Bhd.

Rouhani, A. (2008). An Investigation into Emotional Intelligence, Foreign Language Anxiety and Empathy Through a Cognitive-Affective Course in an EFL Context. Linguistic Online 34, 2/2008, 41-57.

Shaw, D. (2010). Bibliotheraphy: A Cross Discipline Course for Teacher and Counselors. Retrieved December 15, 2010, from www.hiceducation.org/edu_proceedings/Darla\%20shaw.pdf

Shahabudin, H., Mahani R., Ramlah, J. (2007). Psikologi Pendidikan. Bentong. PTS Publication and Distributors Sdn. Bhd.

Spiro, S. (1984). Metacomprehension. Retrieved from Urbana, I.L:ERIC Clearington on Reading and Communication.

Talebinejad, M.R. \& Fard, Z.R. (2012). The Relationship between Emotional Quotient Sosioeconomic Status and Perfomance in Reading Comprehension: A Case Study of Iranian High School Students, Journal of Language Teaching and Research, Vol. 3., No.5, September 2012, 844-850

Tang, H.N dan Moore, D.W (1992). Effect of Cognitive and Metacognitive Prereading. Educational Psychology 12(3), 315-332.

Weare, K. (2004). Developing the Emotionally Literate School. London: Paul Chapman Publishing.

Yopp, H. (2006). Literature Based Reading Activities, 4th Edition. Boston, U.S.A.: Allyn and Bacon.

Yusfarina, M.Y., Abdul Rasid, J.,Zaitul Azma, Z.H.,Samsilah, R., Maslawati, M.(2012) "Emotional Quotient Based Reading Comprehension Strategy", International Conference on Education and New Learning Technologies, $2^{\text {nd }}-4^{\text {th }}$ of July, 2012, Barcelona, Spain.

Zarafshan, M. \& Ardeshiri, M (2012).Relationship between Emotional Intelligence, Language Learning Strategies and English Proficiency Among Iranian EFL. University Student, Journal of Educational and Instructional Studies in The World, August, 2012, Volume; 2, Issue: 3, Article 11, 5-14.

\section{Appendix 1}

Example of Guiding Questions

1. Can you state the place and time settings for this story.

2. Name the main characters.

3. Name the most important character in this story.

4. What is the central issue in this story?

5. How does the main character try to solve the issue?

6. Is it difficult for the character to solve the issue?

7. Explain the lesson acquired from this story.

8. Can you think of an entirely different ending from the one written by the author of the story?

Adapted from: Idol, L (1987). 